\title{
Value Evaluation of Integrated Energy Services Based on Balanced Scorecard
}

\author{
Jun DONG ${ }^{1, a}$, Gui-yuan XUE ${ }^{1, b}$ and $\mathrm{Xu} \mathrm{LI}^{1, \mathrm{c}, \text { * }}$ \\ ${ }^{1}$ North China Electric Power University, Beijing, China \\ aguiyuanxue@126.com, bdongjun221624@163.com, m13051612801@163.com \\ ${ }^{*}$ Corresponding author
}

Keywords: Integrated energy service, Energy service company, Balanced scorecard, Value evaluation system.

\begin{abstract}
To solve the increasingly prominent energy problem, improve the efficiency of energy utilization and reduce energy waste, the state has staged a series of policy laws and regulations to support energy conservation and environmental protection and to develop the energy services. As energy service suppliers, energy service companies mainly use Energy Performance Contracting to perform energy-saving renovation for energy-using enterprise, which can improve the energy efficiency. Research of value for energy services not only help to promote the development of energy service companies and the whole energy service industry, also help to promote energy saving and emission reduction. This paper defines the connotation of the integrated energy services and its value, and on the basis of the traditional balanced scorecard, forms a theory framework of integrated energy services value evaluation system. Finally, it establishes the integrated energy services value evaluation system containing 27 indexes from four dimensions, namely the integrated benefit, the customer cooperation ability, project internal performance and core competence.
\end{abstract}

\section{Introduction}

As energy issues become increasingly prominent, in recent years, Chinese government attaches great importance to the development of energy services industry. In the 12th five-year plan outline, the energy-saving and environmental protection is regarded as the first of seven strategic emerging industries, and it focuses on fostering and developing Energy Service Companies, namely ESC, which is the product of this situation. However, due to the current energy service companies with high suspicion and low acceptance, it is difficult to stimulate the market potential demand customer, national policy guidance provides a good policy environment and technical environment for the development of energy service companies, and also poses challenges to the healthy development of the energy services industry at the same time.

Energy services are based on the requirements (and needs) of customer energy use (industrial steam, heating, cooling, lighting, power, etc.), by means of supply and reasonable distribution, conversion and use links to provide advantageous to the environmental, economical and complete package solution as much as possible. The scope and requirements of energy services are energy supply through rational use way to achieve the purpose of reducing business costs and meet the needs of the market.

For energy service companies, integrated energy service is the process that integrates all resources to provide energy service to target customers. For the target customers, it is a 
process of energy service outsourcing. The reduce costs for the customer by implementing a comprehensive energy service is called integrated energy service value. Energy service companies provide comprehensive energy service to target customers, produce integrated energy service value, and at the same time, integrated energy value should be divided among the stakeholders, including the target customer, to realize a win-win goal.

Therefore, energy service companies need to build integrated energy services value evaluation system, to provide theoretical basis for value identifying and sharing. Integrated energy services value evaluation system can also provide reference for the company's project decision-making, help the company to be recognized and accepted by the market, carry out energy services better, and further promote the healthy development of the whole energy services industry. The development of energy service companies and the improvement of the market can stimulate the potential customers in market, encourage more implementation of energy saving projects, a greater degree of energy saving, environmental protection, accelerate the pace of construction of a resource-saving and environment-friendly society.

\section{Literature Review}

From the perspective of service science, integrated energy service focuses more on service integration and integrating internal party's value appreciation and share [1]. The service that energy service companies provide is comprehensive, including project development, energy audit, feasibility study, project design, personnel training, monitoring energy saving, etc. In traditional consulting services there may also have energy audit or project design, however, integrated services have higher integration degree. The benefits of the energy service have strong comprehensiveness, not only involve the interests of customers, but also contain energy service companies and the interests of relevant interest group. In addition, energy services create value through energy service companies and customers together, which requires share people, technology, information and other elements, to set up perfect service system.

Domestic and foreign scholars on the research of the service value are generally starting from the perspective of the service system. Literature [2] and literature [3] were studied from different angles and levels of ecosystem services value, of which the eyes in the literature [2] have focused on using various methods to estimate the marginal service value of natural capital. Literature [3] is made in value coefficient of accordance with urban ecosystem service. Literature [4] set points from different function level indicator, and built the value evaluation model of information system services, in order to realize the unification of the economic and social value.

Most scholars at home and abroad research from the enterprise level or market level to build indicators about energy services value evaluation system of research, and many of them analyze service projects or energy service companies by some economic indicators. Literature [5] constructed the comprehensive analysis of multistage fuzzy hierarchy evaluation model by using the fuzzy comprehensive analysis method, and analyzed the energy service companies from three aspects of energy saving technology, capital situation and the company management system in the analysis process. Literature [6] built the evaluation index system of contract energy management project from capital, management, policy, market and earnings five aspects by the method of improving analytic hierarchy.

There are a lot of researches on the application of Balanced Scorecard in China, and most of them are concentrated in the financial industry. The Literature [7] studies the application and 
difficulty of the Balanced Scorecard in the performance management, analyze the reasons for the failure of the enterprises in the domestic enterprises, and points out the countermeasures should be taken. Based on the idea of Balanced Scorecard, the literature [8] and [9] construct the performance evaluation system of state-owned commercial banks and proves that the application of balanced scorecard can make up some deficiencies of the original performance evaluation system. Literature [10] summarizes the basic elements of the Balanced Scorecard in the application of the commercial banks in our country, which can really play effectiveness of performance evaluation and strategic management.

Using the Balanced Scorecard theory from the perspective of the Energy Service Companies in this study, it studies how to combine the financial and non-financial indicators to assess the value of integrated energy services from the enterprise, customer, social, environmental multi-layer and build a comprehensive energy service value assessment system. Guided by the theory, the value identification of the comprehensive energy service is provided for reference, which can promote the development of the energy service industry.

\section{Integrated Energy Service Value Evaluation System}

This study based on the theoretical framework of the balanced scorecard, make the traditional "financial" dimension extend to include social, economic and environmental comprehensive benefit dimensions, "customer" dimension is correct to customer cooperate ability dimension, "internal process" and "learning and growth" dimension respectively for project internal performance and core competence dimensions to realize the value evaluation of comprehensive energy service.

Table 1. Integrated energy service value of 27 indicators evaluation system

\begin{tabular}{|c|c|}
\hline \multirow{6}{*}{$\begin{array}{c}\text { Integrative } \\
\text { efficiency } \\
\text { evaluation index }\end{array}$} & Unit GDP energy consumption \\
\hline & Electricity utilization efficiency \\
\hline & electricity production efficiency \\
\hline & Integrated energy service utility ratio \\
\hline & Annual net benefits \\
\hline & Environmental improvement index \\
\hline \multirow{7}{*}{$\begin{array}{l}\text { Customer } \\
\text { cooperation } \\
\text { ability index }\end{array}$} & Payment credit \\
\hline & Assets structure proportion \\
\hline & Risk tolerance index \\
\hline & User participation index \\
\hline & operational status evaluation \\
\hline & Environment protect contribution index \\
\hline & Corporate image/ Brand value index \\
\hline \multirow{8}{*}{$\begin{array}{l}\text { Project internal } \\
\text { performance } \\
\text { evaluation index }\end{array}$} & Unit power saving costs \\
\hline & Can-be-used electricity cost \\
\hline & investment recovery period \\
\hline & National preferential policies adapting degree \\
\hline & Local government financial support proportion \\
\hline & financing channels evaluation \\
\hline & service effectiveness implementation rate \\
\hline & users projects late fault responsibility \\
\hline \multirow{6}{*}{$\begin{array}{l}\text { Core competence } \\
\text { evaluation index }\end{array}$} & $\mathrm{R} \& \mathrm{D}$ ratio \\
\hline & Technical renovation investment ratio \\
\hline & Training investment ratio \\
\hline & Environmental protection investment ratio \\
\hline & Proportion of professionals \\
\hline & Patent quantity \\
\hline
\end{tabular}


The value of comprehensive energy service is made up of a variety of elements constitute a organic whole, the index system of the construction of evaluation system must not only follow the general principles of objectivity, practicability and systemic design, but also conform to five balance principle of the balanced scorecard. In this paper, from the last section, four dimensions of comprehensive benefits, customer cooperation ability, project internal performance and core competence, established a integrated energy service value of 27 indicators evaluation system, as shown in Table 1.

(1) The main consideration of Integrated benefit evaluation index is the total benefits of economic, social and environment.

Unit GDP energy consumption = $($ Total electricity consumption - Electricity consumption of resident) / GDP, it reflects changes in the rate of social electricity and change the way of economic growth.

Electricity utilization efficiency $=$ Total electricity consumption $/$ Social benefits, it reflect people's living standard.

Electricity production efficiency $=($ Generating cost + Power supply cost $) /$ Total power supply, it reflects the efficiency of energy service project and the supply side.

Integrated energy service utility ratio $=$ Quantity of intra - regional applications integrated energy service / Quantity of intra - regional enterprises

Annual net benefits $=$ Benefits of integrated energy service project - cost of the project, measure whether the project can reap the benefits.

Environmental improvement index $=($ Emission reduction power plant + Integrated energy service project emission reduction) / emission reduction of the whole society

(2) The main consideration of customer cooperation ability index is the payment capacity credit level and risk level of the energy - consuming enterprise

Payment credit, according to the user's credit history, will measure the performance of the contract, pay on time and share the benefits.

Payment capacity index, it reflects the capital of the users and measure whether it has payment capacity by the proportion of assets structure

Risk tolerance index, it reflects the user's risk appetite and tolerance and affect the design of the project implementation plan.

User participation index, it reflects the participation degree of the user in the process of the project implementation and focus on the user itself control ability.

Operational status evaluation, it reflects the enterprise's production status, short-term operation, etc.

Environment protect contribution index, it measures the user enterprise's performance and ability of creating value

Corporate image / Brand value index, it measures the intra - regional status of the user enterprise and judge the strength of support in the process of integrated energy services project implementation.

(3) Project internal performance evaluation index mainly considering the efficiency in the specific implementation process of the integrated energy service project.

(4) $R \& D$ ratio, Technical renovation investment ratio, Training investment ratio, Environmental protection investment ratio, Proportion of professionals, Patent quantity, They reflect the development potential in the process that integrated energy service companies implement the project, in such aspects as technology, intellectual property, human resources, and evaluate the core competence of the enterprise provide service to users. 


\section{Conclusion}

From the build process of the integrated energy services valuation indicators, we can see energy services is a very complex product, it requires energy service company broad knowledge and professional capabilities, it also requires customers have a certain energy services basic embodiment and have a high commendation to the entire system. This is because in the course of the promotion of energy services, customers may not know the incomplete use of energy, and do not believe the integrated energy services have the potential to reduce energy costs, and do not believe that if it can really reduce costs and improve efficiency. The size, and operating conditions, and management capacity of energy companies have an important impact on the implementation of energy services. Energy service companies need to take some measures, to do publicity work, change the customer's way of thinking, at the same time establish a set of criteria for decision-making of the customers. Due to the specific implementation of the project is at the entire energy market environment, it is necessary to make full use of resources that already exist in the market, but also to take some measures to create the necessary conditions for the energy services market, in order to improve the overall efficiency of the energy services. You can formulate the quality standards for energy services and energy services company, to establish cooperation networks in order to joint energy service companies with banks, government departments, to promote public service and private combination project and so on. Finally, the purpose of energy services is to reduce costs, improve efficiency. The key of creating sustainable value for all stakeholders in the system of energy services is the technical innovation, staff development and cultural construction. Therefore, technological innovation strength is essential for long-term development of energy service company and energy companies.

Setting out a value evaluation system for integrated energy service with four dimensions that include integrated benefit, the customer cooperation ability, project internal performance and core competence, combines external and internal factors, economic and non-economic factors, can provide decision-making basis for the selection of integrated energy service and implementation, but also provide a theoretical basis for the research of the value sharing mechanism of followed energy service and the behavior of stakeholders.

\section{Reference}

[1] Dong Wei, Jie Yue, and Yanyan Ju, Energy saving service value analysis in the contract energy management, Int. J. China's population, resources and environment, Vol.20, pp. 379-384, 2012

[2] Gaodi Xie, Chunxia Lu, Shengkui Cheng, The global ecosystem services value evaluation research progress, Int. J. resource science,Vol.23,pp.5-9,2001

[3] Fengtai Zhang, Weici Su, and Weiquan Zhao, Based on land use/cover change of chongqing urban ecosystem service value research, Int. J. ecology and rural environment Journal,Vol.24,pp.21-25,2008

[4] Shaohua He and Bin Kang, Information value and information service value evaluation research, Int. J. library information service, Vol.49, pp.72-75, 2005

[5] Xin Wang,Zhenyan Xu, and Tao Chen, Energy efficiency EPC mode in the large-scale public building selection research, Int. J. energy conservation in building, Vol.1,pp.76-80,2011 
[6] Tiancheng Shang and Junxiong Guo, Contract energy management project evaluation, Int. J. Journal of Beijing institute of technology (social science edition), Vol.13,pp.11-14,2001

[7] Yang Cao, The application and difficult point analysis of balanced scorecard in performance management, Int. J. Market weekly, theory research, Vol.3, pp.73-74, 2009

[8] Ying An, The balanced scorecard in the use of performance evaluation system of commercial Banks in our country, Int. j. commercial economy, Vol.12, pp.104-106

[9] Yang Li, The balanced scorecard in the application of performance evaluation of state-owned commercial Banks in our country, Int. J. financial research in Guangxi, Vol.11, pp.26-42

[10]Zhendai Yang and Zijiang Jin, Several elements of the balanced scorecard's successful application in Chinese commercial Banks, Int. J. performance management, Vol.6, pp.24-27 